\title{
BABEL INSACIÁVEL
}

\author{
Modernidade E URbaniZAÇÃo nOS EsTAdos Unidos \\ Conforme Paul Vidal de la Blache
}

\author{
Guilherme Ribeiro
}

R E S U M O Tendo como ponto de partida o artigo A travers l'Amérique du Nord, publicado em $1905 \mathrm{em}$ La Revue de Paris, pretende-se discutir os impactos da experiência norte-americana na geografia de Vidal de la Blache. Destacando seu interesse para com o fenômeno urbano, pretendemos apresentá-lo como um importante intérprete da modernidade.

P A L A V R A S - C H A V E Modernidade; urbanização; Estados Unidos; Paul Vidal de la Blache; geografia.

\section{A PROPÓSITO DA HISTÓRIA DO PENSAMENTO GEOGRÁFICO E DA ATUALIDADE DO PENSAMENTO DE VIDAL DE LA BLACHE}

De modo geral, temos a impressão de que os geógrafos não valorizam suas obras e seus autores considerados clássicos. Embora nos últimos tempos seja possível constatar um interesse crescente pela história e epistemologia geográficas (inclusive dos estudantes de graduação), quando comparamos o tratamento que a Sociologia, a História e a Economia conferem a Émile Durkheim, Max Weber, Marc Bloch, Lucien Febvre, Karl Marx e Adam Smith, percebemos que ainda existe um longo caminho a trilhar no tocante à necessidade de um investimento mais rigoroso por parte da Geografia ao redor das heranças de Humboldt, Ritter, Ratzel, Hettner, Vidal de la Blache, Demangeon, Brunhes, Sauer, Hartshorne, Darby e outros. Estamos falando de autores extremamente complexos cujas ideias, conceitos e métodos são negligenciados por uma ciência que parece não ter olhos senão para o tempo presente. Nesse sentido, a história do pensamento geográfico possui muitas dificuldades de consolidar-se enquanto domínio de pesquisas, restando à mesma $\mathrm{o}$ papel de ser apenas mais uma disciplina a compor o primeiro ano da graduação.

Não são poucos os problemas decorrentes dessa situação. Num momento em que as Ciências Humanas passam por uma fase de renovação epistemológica extremamente fértil, a Geografia deve aproveitar a ocasião e atentar para seus clássicos. Não existe avanço científico que possa prescindir das contribuições de outrora. Na verdade, aqueles que conhecem um pouco dos debates no âmbito da teoria da história sabem que o passado é uma construção do presente. Portanto, um olhar atento sobre os rumos tomados pela história do pensamento geográfico não se contentaria em acreditar numa explicação falaciosa e ingênua de que os geógrafos de ontem estão ultrapassados e que suas reflexões são "datadas". Após os esforços de Foucault, sabemos perfeitamente que a produção científica é regida por uma ordem discursiva cujas exclusóes (de temas, conceitos, objetos e autores) devem ser estudadas com tanto apuro quanto as inclusões (Foucault, 2004 [1970]). Umas explicam as outras e vice-versa. Assim, pensando no movimento que caracteriza a trajetória das correntes geográficas, o balanço que se pode fazer acerca do impacto do neopositivismo e 
do marxismo foi o de um verdadeiro expurgo da Geografia Clássica. Sobre Ratzel e Vidal, por exemplo, recaiu a pecha do determinismo e a do empirismo regional, respectivamente, deixando de lado toda a riqueza de suas obras que, nas últimas décadas, alguns autores vêm ensaiando resgatar (Carvalho, 1997, 1997a; Sanguin, 1990; Ribeiro, 2007, 2008).

Além disso, cremos que os estudos em torno do pensamento geográfico têm enfatizado em demasia os aspectos teórico-metodológicos em detrimento do contexto histórico. Essa démarche distorce tanto a compreensão destes aspectos quanto um entendimento mais amplo de como as ideias geográficas são indissociáveis dos processos históricos vivenciados pelos geógrafos. Tem-se a impressão de que a Geografia é uma sucessão linear de conceitos, métodos e teorias; no limite, há quase que uma teleologia, como se o passado não tivesse outro propósito senão ter "preparado" as condiçōes "ideais" para o estabelecimento daquela que, a partir de então, será a corrente a desbancar as demais. Não foi assim com a Geografia Radical/Crítica? Portanto, se não apreendermos a história do pensamento geográfico com o devido apreço que este campo merece, a saber, enquanto algo fundamental para a formação de todo e qualquer geógrafo que precisa assimilar a natureza de seu ofício, continuaremos a tratar de modo insatisfatório e, na maioria das vezes, enviesado, debates como a questão do objeto, os vínculos Geografia Humana-Geografia Física, a relação sociedade-natureza, o diálogo com as demais ciências, o papel devido da Geopolítica etc.

No intuito de acentuar a história do pensamento geográfico e resgatar a importância de Vidal de la Blache, o artigo A travers l'Amérique du Nord, publicado em 1905 em La Revue de Paris (Vidal de la Blache, 1905), nos permite vislumbrar um geógrafo que, com certeza, esteve à frente de seu tempo, posto que antecipou determinados elementos que fariam parte do temário geográfico durante todo o decorrer do século XX. Como temos sustentado, nossa hipótese é a de que Vidal pode ser interpretado como um perspicaz intérprete da Modernidade (Ribeiro, 2008, 2010, 2012), isto é, como um intelectual que soube compreender profundamente alguns dos principais dilemas de sua época. A saber:

- a complexa delimitação das fronteiras dos Estados Nacionais;

- as consequências políticas e geopolíticas referentes às atividades de découpage do espaço;

- as disputas colonialistas na África e na Ásia pela hegemonia econômica e geopolítica mundial;

- as tensóes territoriais internas ao continente europeu, com destaque para o conflito França-Alemanha;

- a emergência da urbanização e da industrialização e seus desdobramentos no território francês;

- a centralidade assumida pelas cidades naquilo que mais tarde seria denominado produção do espaço geográfico.

Não por acaso podemos sustentar a visível atualidade do pensamento vidaliano. Sim, pois além de constituir-se num capítulo crucial da história da Geografia, ao vislumbrar questôes típicas do mundo moderno ele tocou em pontos que nos são caros até hoje. No que concerne aos elementos epistemológicos, ao tomar como princípio a unidade terrestre, operar uma sofisticada articulação de escalas e investigar a diversidade de gêneros de vida ao redor do globo, nosso investigado parecia antecipar em décadas o que os geógrafos de hoje costumam apresentar, muitas vezes, como novidade. Apresentado esse quadro, tudo nos leva a crer que Vidal esboçou uma agenda empírica e epistemológica extremamente útil no entendimento de um mundo cada vez mais global. 


\section{FERROVIAS, PAISAGENS, CIDADES: A AMÉRICA E A MODERNIDADE SOB O PRISMA GEOGRÁFICO}

A travers l'Amérique du Nord, de 1905, é um daqueles textos que não foram canonizados pelos estudiosos da obra vidaliana. Dos três grandes artigos que discutem a questão regional em Vidal (Ozouf-Marignier \& Robic, 1995; Mercier, 1998, 2001), nenhum deles lhe faz referência. Outros dois trabalhos que cobriram satisfatoriamente a bibliografia vidaliana também não o mencionam (Sanguin, 1993; Soubeyran, 1997), exceção feita a Claval (Claval, 1998).

Além desta importante observação, o que mais esse artigo esquecido possui de interessante? E, graças mesmo a essa condição, em que medida ele lança novas luzes sobre a geografia de Vidal de la Blache?

Em 1904, ao lado de nomes do porte do alemão Alfred Penck e do americano William Morris Davis, Vidal participou do VIII Congresso Internacional de Geografia em Washington. Este Congresso contou com um grande trabalho de campo ao Oeste dos Estados Unidos e, ao final das sessões, ao México (Zimmerman, 1904; De Martonne, 1905; Froidevaux, 1905).

O principal aspecto a ser destacado das impressões de Vidal reside nas observaçôes sobre a urbanização e o modo de vida americanos - operadas sob uma perspectiva eurocêntrica, cumpre ressaltar. ${ }^{1}$ Lançando mão da comparação e da descrição como feições metodológicas, Vidal encarna um típico representante do Velho Continente surpreendido positiva e negativamente ao mesmo tempo diante de um "país novo". ${ }^{2}$ Suas anotações demonstram uma apurada descrição da paisagem, conceito revelador de processos históricos, relações sociais e da transformação do meio (vide Vidal de la Blache, 1908). Seus registros ao redor dos hábitos e costumes norte-americanos possuem um claro matiz "etnográfico", reverberando o forte impacto da Sociologia e da Antropologia de viés durkheimiano daquele período (consulte Vidal de la Blache, 1902, 1904).

Em todo caso, são as cidades que lhe atraem. Elas representam a pujança da América, espaço organizador da circulação e das trocas econômicas, lócus privilegiado do Americanismo (vide definição a seguir). Ele usa o termo algumas vezes e nota que tal traço afeta, inclusive, a canadense Montreal. Todavia, as cidades também são lugares de encontros. À semelhança de um flâneur, Vidal delineia arranha-céus, buildings, ruas mal iluminadas de dia, porém plenas de movimento e luzes artificiais à noite, estações sem vida - quando comparadas às francesas e seus Cafés - contrastando com a animação nos halls dos hotéis, boutiques diversas, vias férreas, trolleys, fios telegráficos.

Eis que estamos diante de uma situação interessante. No engatinhar do século XX, um geógrafo nascido num continente e num país tidos como os berços da Modernidade descobre, ao mesmo tempo entusiasmado e espantado, como a América do Norte processa e vivencia sua face moderna. E, na comparação com a Europa, temos a nítida sensação de que, enquanto esta representa o passado, a tradição e as mudanças lentas, os Estados Unidos incorporam a rapidez, as técnicas, o futuro. De modo significativo, a história dos EUA descolou-se da herança europeia. Não se trata nem de uma cópia, nem de uma imposição do Velho Continente, mas de outra coisa. Existem especificidades geográficas nos Estados Unidos e Vidal de la Blache, mesmo que sem aprofundá-las, identificou-as com nitidez.

Assim, um novo espaço - aliás, Vidal usa esse vocábulo diversas vezes, o que pode ser assimilado como a representação de um meio geográfico cada vez mais humanizado - significa um novo modo de vida. Uma dinâmica original no tocante à relação com o entorno,
1 Ainda que o texto estampe "América do Norte" no título, ele passa rapidamente sobre o Canadá - bem como sobre o México.

2 Expressão utilizada pelo historiador francês Fernand Braudel a propósito do Brasil, país onde viveu e ajudou a fundar a Universidade de São Paulo nos anos 30 (Braudel, 1997 [1935]). 
3 "É também uma obra coletiva - e ainda mais metodicamente levada adiante - aquela inaugurada em 1870 pelo Geological Survey dos Estados Unidos alguns meses após a abertura do primeiro caminho de ferro transcontinental. No momento em que a locomotiva começou a perturbar, nos desertos e oásis, os Mórmons que lá tinham fundado a Nova-Jerusalém, o interior das Montanhas Rochosas e mesmo seus acessos a $1^{\prime} \mathrm{W}$ do meridiano de $100^{\circ}$ ainda eram um mundo quase desconhecido. Há dez anos, uma missão enviada ao Colorado não tinha feito mais que entrever a estranheza desta "província de platôs", "acumulação de rochas nuas, de formas gigantescas superpostas e coloração intensa", que rasgam os canyons cravados em até $1800 \mathrm{~m}$ de profundidade. Então começa a exploração do Grande-Oeste e, por uma série de reconhecimentos sistemáticos, para além do alto Missouri e do S. do Rio Verde, foi revelado em detalhes um dos tipos mais surpreendentes da região árida" (Vidal de la Blache, 1899, p. 104).

4 "Na América, foram as Prairies-States (Ohio, Indiana, Illinois, lowa) que, quando cultivadas por volta de 1860, inauguraram, por necessidade - sobre esse território quase igual ao conjunto da França -, um grande emprego de máquinas. Lá se constituiu, pelo maquinismo e pelo uso de instrumentos mais leves do que na Europa, um novo tipo agrícola, transportado desde então para o Canadá e para o Oeste e em vias, talvez (ao menos na medida em que os solos se prestam a isso), de dar a volta ao mundo" (Vidal de la Blache, 1911a, p. 292). com o ambiente. Grandes distâncias e grandes cidades exigem domínio de técnicas de transporte e de comunicações, desenhando na paisagem formas e conteúdos assaz diversos dos quais Vidal estava habituado. Na realidade, como indicamos noutra ocasião (Ribeiro, 2007), mesmo quando ele não conhecia os Estados Unidos, o processo de ocupação territorial deste país já havia lhe chamado atenção. Nos artigos Leçon d'ouverture du cours de Géographie $^{3}$ (aula inaugural no Instituto de Geografia da Sorbonne em 1899) e Les conditions géographiques des faits sociaux, de 1902, ele mostra que as dimensões do território norte-americano e seus obstáculos naturais foram superados pela energia e pela vitalidade dos procedimentos de indústria e engenharia lá desenvolvidos. Por intermédio da técnica, tema recorrente em suas análises (Ribeiro, 2011), a hostilidade geográfica inicial foi convertida em matriz para o progresso. Impactando não apenas a cidade, mas também o campo, ${ }^{4}$ o resultado é o que ele denominou, sintomaticamente, de Americanismo:

O desenvolvimento da força mecânica, sob todas as formas (vapor ou força hidráulica) e níveis (do elevador gigantesco às aplicaçôes mais minuciosas, delicadas), tornou-se a marca do Americanismo. A existência de um instrumental de transporte incomparável não deixou de influenciar a mentalidade americana. Às facilidades de locomoção, são adaptados hábitos de vida distintos dos nossos (Vidal de la Blache, 1902, p. 20, grifo nosso).

A despeito de comentários nem tão elegantes assim sobre a Estátua da Liberdade, a arquitetura pastiche de parte das cidades e certa infantilidade do homem norte-americano, Vidal parece considerar com bons olhos o desenvolvimento da antiga colônia britânica, apreciando um dinamismo inexistente na França e na Europa. Quando termina sua breve exposição sobre Montreal, por exemplo, revela que é com dificuldades que deixará seus compatriotas e seu passado. Porém, de imediato, afirma, referindo-se aos Estados Unidos: "a América não é a terra do passado" (Vidal de la Blache, 1905, p. 515).

Aqui, abre-se uma rica discussão a propósito das relaçôes entre espaço e tempo, entre a diversidade dos lugares e dos saberes locais — fenômeno amiúde evidenciado por Vidal e que, ao nosso ver, pode ser considerado um dos fundamentos de sua geografia - e as temporalidades neles inscritas. No caso em questão, estamos pensando em como o Novo Mundo, comparado ao Velho Continente, suscitou questões interessantes do ponto de vista da teoria da história. Segundo o marxista britânico Eric Hobsbawm, a observação da realidade presente do continente americano iluminava o passado europeu (Ribeiro, 2004). $\mathrm{O}$ annaliste francês Fernand Braudel pensava a mesma coisa, mas foi além. Para ele, o Brasil atuou como um laboratório pleno de liçôes temporais: a chance de compreender diferentes ritmos; a observação do mar Mediterrâneo por outro ângulo; a não linearidade da história (Braudel apud Daix, 1999 [1995], p. 162; Paris, 1999; Ribeiro, 2008a; Lima, 2009).

Se, como é de praxe, os historiadores exercem seu ofício atentando para as conexões passado-presente, igualmente o faria Vidal de la Blache — historiador de formação, nunca é demais recordar. No sul dos Estados Unidos, na fronteira com o país vizinho, ele antecipa em pelo menos duas décadas o campo e o tema de pesquisas do geógrafo anglo-saxão Carl Sauer: o México e a relevância da paisagem na compreensão da historicidade (Sauer, 1941). Diferente dos Estados Unidos, porém, em Guanajuato a modernidade cede lugar à tradição:

[...] contemplando à direita e à esquerda as fendidas muralhas cor-de-rosa das antigas igrejas espanholas, tem-se o sentimento de mergulhar no passado, num passado que, por si mesmo, 
recua cada vez mais seus limites, pois, sob o verniz depositado pelos conquistadores, o velho fundo indígena manifesta-se nos tipos, nas ocupaçôes, na adaptação secular ao solo. Uma América pretérita se deixa entrever (Vidal de la Blache, 1905, p. 528).

Todavia, privilegiado por sua dupla condição, ou seja, falando desta vez como geógrafo, sua preocupação recai majoritariamente sobre o tempo presente. A efervescência da nação do Norte implica numa composição temporal distinta da que o autor reconhece na cidade-luz.

Numa cidade de desenvolvimento histórico regular como Paris, os aportes dos séculos se justapõem e se sucedem tal como, no tronco de uma árvore, os anéis concêntricos correspondem aos períodos de crescimento. Em Nova Iorque, o presente simplesmente se sobrepõe ao passado (ibidem, p. 525).

“O presente se sobrepõe ao passado". Eis uma adequada epígrafe da Modernidade: o ultrapassar das tradições, a intensa experiência trazida pelo novo, a cidade como centro das atenções, outra vivência espaço-temporal (Matos, 2010; Berman, 1986 [1982]; Harvey, 1992 [1989]). Nessa conjuntura, há que se separar o papel das cidades e das vias férreas. Tributárias de sua temporada americana, as cidades e as ferrovias teriam convencido Vidal de que a estrutura de comunicaçôes e a organização regional influenciavam no desenvolvimento econômico de uma nação (Claval, 2007, p. 71).

Indubitavelmente, os desdobramentos das ferrovias são bastante significativos: assumiram papel estratégico em termos político-econômicos para o Estado-Nação; trouxeram uma nova dinâmica às cidades; interligaram regióes e territórios através das redes; possibilitaram a ocupação efetiva de determinados espaços outrora inóspitos. E, na verdade, uma visada na obra vidaliana nos ensina que ele sempre esteve atento às estradas de ferro - tópico que, no plano mais geral, demonstra sua atenção diante da circulação (Vidal de la Blache, 1996-97 [1902]; Robic, 1996-97; Claval, 2001) e das comunicaçôes construindo uma rede de ligaçôes verdadeiramente mundial, um "sistema mundial" (cf. Arrault, 2008). Foi assim que, retirando exemplos de todas as partes do globo, observou a rigidez da estrutura ferroviária francesa, tida como lenta perante aos desafios da modernidade (Vidal de la Blache, 1994 [1917], p. 249); o transporte de grãos da Ucrânia aos portos do Ocidente (Vidal de la Blache, 1873); o perigo, para os negócios franceses, da formação de um monopólio no Peru, após um sindicato mineiro norte-americano ter ampliado a via férrea de Oroya a Cerro de Pasco (Vidal de la Blache, 1906, p. 79); a finalização em 1885 da principal ferrovia canadense, a Canadian Pacific, que introduziu a província da Colúmbia Britânica no mercado internacional (Vidal de la Blache, 1908a, p. 366).

Em suma, para ele os trilhos valorizaram a América (Vidal de la Blache, 1954 [1921], p. 335-8), e é por essa razão que no artigo Les chemins de fer en Amérique ele destaca a data de 10 de maio de 1869:

Onde, pela primeira vez, os trilhos alcançaram, por São Francisco, o Oceano Pacífico. Construída para acelerar a colonização da Califórnia e para sancionar através da região árida a união do Leste com o Oeste, a Union and Central Pacific foi um grande acontecimento e, sobretudo, um grande sinal. Assim, pela primeira vez, foi traçada através de um continente uma faixa contínua de $5259 \mathrm{~km}$ de vias férreas. Para a América, a data permanecerá tão 
memorável quanto para nós seria, seis meses mais tarde, a abertura do Canal de Suez (Vidal de la Blache, 1912, p. 74).

É um pouco também nesse sentido que constatou, admirado, não só o tamanho das grandes cidades e seus arranha-céus, mas, essencialmente, a natureza da urbanização norte-americana. Mencionando cidades como Chicago, Philadelphia, Saint-Louis (local da sessão de encerramento do Congresso) e, com destaque, Nova Iorque, ele aponta a especialização da vida urbana e seus bairros universitários, familiares e de negócios (Vidal de la Blache, 1905, p. 518); a fusão de traços citadinos e rurais distribuídos por uma ampla extensão, algo não encontrado nos subúrbios de nenhuma grande cidade europeia (idem, p. 521); e um certo descompasso num crescimento acelerado próprio de adolescentes (ibidem, p. 521). Por essas e outras razões, declara:

Se quisermos observar a vida urbana entregue a si mesmo, agindo com todo o seu vigor, é sobretudo nos Estados Unidos que importa estudá-la. A necessidade de dominar a distância, de reunir vastos espaços em um domínio econômico, impóe-se lá [...] enxameando em redor, estendendo indefinidamente os seus bairros suburbanos, a cidade é a mais perfeita expressão do Americanismo (Vidal de la Blache, 1954 [1921], p. 383-7).

Porém, mais que isso, três aspectos são cruciais, reveladores da sensibilidade de Vidal diante de como a modernidade se expressava nos Estados Unidos:

(i) as grandes cidades enquanto "regiōes urbanas";

(ii) a existência de "cidades mundiais";

(iii)a "concentração" como arranjo espacial típico do americanismo.

Tal como dissemos anteriormente, são estas algumas das especificidades geográficas norte-americanas - que, decerto, contrastavam com as manifestações urbanas na França. Uma olhada rápida no Tableau géographique de la France, publicado apenas dois anos antes de $A$ travers l'Amérique du Nord, nos permite inferir a dimensão dessa diferenciação e, de maneira geral, do desenvolvimento da urbanização nos dois lados do Atlântico (Vidal de la Blache, 2007 [1903]). Afinal, conforme ele próprio declarara,

A personalidade dessas grandes cidades americanas é difícil de discernir; é menos uma cidade que uma regiāo urbana, um amálgama no qual várias cidades coexistem em uma só (Vidal de la Blache, 1905, p. 521, grifo nosso).

Entretanto, segundo a observação de Claval, Vidal constataria que as enraizadas estruturas rurais francesas também começavam a ser revolvidas, conformando-se em matéria constante até sua morte em 1918: o impacto geográfico da urbanização e da industrialização na modernização do território francês, discutido com apuro nos anos 1910, 1911, 1916 e 1917 em artigos primordiais como Régions françaises, La relativité des divisions régionales, Évolution de la population en Alsace-Lorraine et dans les départements limitrophes, La rénovation de la vie régionale e, notadamente, o livro La France de l'Est: Lorraine-Alsace (Vidal de la Blache, 1910, 1911, 1916, 1917, 1994 [1917]).

Mesmo que as velhas rotas permanecessem no imaginário popular, continuando a servir como limites entre propriedades e comunas (Vidal de la Blache, 1996-97 [1902]), os lugares e os quadros fixos de outrora seriam necessariamente modificados (Vidal de la Blache, 1916; Ribeiro, 2008b). Tendo a dinâmica urbano-industrial como leitmotiv, 
Paris, Lyon e Mulhouse, por exemplo, passariam a polarizar grandes espaços, irrigando o Hexágono com suas respectivas áreas de influência (vide Vlach, 1999). Diante de novas formas de organização dos transportes, produção, comunicação e serviços que, a seu turno, engendravam novas escalas, Vidal tentaria apreender esses conteúdos. Em 1911, afirmava que "O princípio de agrupamento não é mais fundado sobre a homogeneidade regional, mas sobre a solidariedade entre regiões diversas" (Vidal de la Blache, 1911, p. 6). Anos mais tarde, complementaria: "Sob sua forma moderna, a ideia regional é uma concepção da indústria; ela se associa à ideia de metrópole industrial” (Vidal de la Blache, 1994 [1917], p. 163). Para tanto, utilizou conceitos como "cidade regional" (Vidal de la Blache, 2007 [1903]) e "nodalidade", este último tomado do britânico Halford Mackinder (Vidal de la Blache, 1910).

Nesse fértil intercâmbio das experiências francesa e norte-americana, embora Vidal não tenha tido a intenção, podemos interpretar os três aspectos acima mencionados como um exercício de antecipação sobre o futuro da urbanização no século XX? Assim, não é com muita dificuldade que podemos observar a correspondência entre as "regiōes urbanas" e o movimento que originaria as megalópoles no final desse mesmo século (Boston-Washington, Rio de Janeiro-São Paulo, Tóquio-Osaka, apenas para citar algumas). Outro paralelo poderia ser estabelecido com as redes de cidades que, em tempos de globalização, reestruturam o espaço regional: as cidades-regiōes globais (Scott, 2001). $\mathrm{Na}$ sequência, não deixa de chamar atenção o fato dele mencionar "cidades mundiais" no ano de 1905, quando sabemos que o debate sobre as mesmas (ainda que o sentido seja outro) deu-se, fundamentalmente, a partir de meados dos anos 1980 e início dos 1990 (vide Sassen, 1991).

Em uma notável passagem do ponto de vista da organização do espaço urbano norte-americano:

Em virtude da solidariedade das empresas, parece que tudo contribui para alcançar e se concentrar num mesmo ponto: concentração extrema para reduzir, ao mínimo, os custos de tempo e de dinheiro; planejamentos proporcionais às grandes massas de homens ou de coisas pelas quais é vantajoso agrupar. Não é nesta combinação que reside o segredo do americano? Segredo de agora em diante testado pelo sucesso, que lhe permite estender seu domínio de ação por todo um continente. Para uma cidade, essas gigantescas construções são o sinal que ela está alcançando a idade da maturidade, de plena força. Os escritores que retraçam sua história registram a data rumo a qual ela iniciou o período arquitetônico dos Sky-Scrapers, "arranha-céus". ${ }^{5}$ Daí em diante, toda cidade que chega a esse estágio pode assumir um lugar na constelação das cidades mundiais que disputam o record. Ela adquiriu seus galardōes. Os buildings se erguem à porfia uns dos outros. Eu os vi em Nova York, onde os negócios e as ocupaçôes da vida tomavam até três quartos de altura, enquanto a Babel insaciável continuava a superpôr andares e subir em direção ao céu (Vidal de la Blache, 1905, p. 526, grifo nosso à exceção dos termos em inglês).

Amparado pela análise em retrospectiva e por uma visão ampliada da história do pensamento geográfico, não parece que o geógrafo francês estava descrevendo o arranjo espacial que, nas décadas seguintes, caracterizaria o fordismo? Seria exagero sustentar que parte de seu raciocínio esboçava o modelo hegemônico de organização espacial do século XX, pautado na verticalização, na concentração ${ }^{6}$ e na urbanização completa da sociedade?
5 Em Saint-Louis, "Em 1885 [...], começou a era dos arranha-céus da construção arquitetônica, que transformou a aparência física da seção de negócios de Saint-Louis" (The State of Missouri, Annales autobiography, editada por Walter Williams, 1904, p. 251) (Nota extraída do original).

6 Embora não esteja tratando da América, em La relativité des divisions régionales, texto em que mostra toda sua capacidade enquanto um grande intérprete das cidades e de como seus papéis econômicos alteraram as regiões francesas, ele dá um salto no tempo e nos ensina que "Esse fenômeno de concentração ainda se manifesta geograficamente sob outra forma. Ele permite que muitas cidades coexistam sem se prejudicar, a favor da especialização do trabalho, sobre os próprios lugares em que estão reunidos componentes de uma vida intensa. Diferindo umas das outras pelas diversas produções às quais se dedicam, beneficiam-se do proveito comum das facilidades de crédito, relações, transporte, mão de obra e, em consequência, da diminuição das distâncias entre elas. Lille, Roubaix e Tourcoing tendem a formar um único grupo, como fazem alhures Elberfeld-Barmen, Manchester-Salford, Liège-Seraing etc. Antigamente, era a tendência inversa que prevalecia. De posse de um gênero de indústria, cada cidade não procurava outra coisa senão evitar a aglomeração em torno dela; visando suprimir todo germe rival. Hoje, a nodalidade, entendendo por esta nova expressão a reunião de todos os auxiliares demandados pela vida comercial e industrial, se sobrepõe a qualquer outra consideração. É ela que, em certas áreas propícias, atrai as cidades umas em direção às outras" (Vidal de la Blache, 1911, p. 10-11).

7 Noção pela qual temos muito apreço e que tomamos de empréstimo do filósofo francês Henri Lefebvre, em seu clássico livro La révolution urbaine (Lefebvre, 1999 [1970]). 
Não por acaso, Vidal faz referência não a uma cidade qualquer, mas àquela cujo valor do terreno - como ele mesmo anota - era mais caro do que no bairro da bolsa de valores de Paris (idem, p. 525). A hoje cosmopolita e multicultural Nova Iorque, um dos maiores centros do capitalismo da história contemporânea, expressão singular do americanismo, o autor supracitado denomina, apropriadamente, Babel insaciável, cidade mundial muito antes que o termo se tornasse célebre. Tudo isso tão somente reforça nossa hipótese: Vidal de la Blache é um poderoso intérprete da Modernidade. E com uma vantagem: não privilegia o tempo em detrimento do espaço, tal como boa parte da tradição intelectual ocidental o fez (Soja, 1993 [1989]), mas antes, conjuga as duas categorias - o que potencializa suas análises.

\section{CONCLUSÃO}

Não podemos terminar estas breves linhas sem antes grifar que, num país onde o meio ambiente possui um caráter "cinematográfico", Vidal opta por destacar sua urbanização. Aqui, eis um bom argumento contra aqueles que afirmam o "passadismo" e o "organicismo" do geógrafo francês. Entretanto, como não poderia deixar de ser, assim como na totalidade da obra vidaliana, nesse texto o tema da natureza também é abordado. Contudo, emerge aqui uma grande novidade. Ele o faz conforme um ponto de vista poucas vezes registrado (vide Vidal de la Blache, 1908b). Em nossos dias, certamente chamaríamos isso de "questão ambiental": ao mesmo tempo em que elogia os espaços abertos ao lazer, ao esporte e às crianças — os parques naturais —, realçando-os enquanto um dos elementos mais originais da vida urbana nos Estados Unidos (Vidal de la Blache, 1905, p. 517), recrimina norte-americanos e franco-canadenses pela relação predatória com a natureza, pela "desnaturalização" (idem) de certas paisagens graças à presença de silos e motores eólicos e pelos "dias contados" da floresta por conta da abertura de canais e ferrovias (ibidem, p. 513-514).

Em uma passagem eloquente:

Em 1903, construiu-se no Texas, o Indian territory, Oklahoma, mais ferrovias do que em qualquer outra parte dos Estados Unidos (3061 km). Igualmente, ao longo de toda a ferrovia, o homem abate a floresta, caça a natureza virgem. Lamentavelmente, consumidos pela metade ou abatidos por incisão, surgem esqueletos de árvores; troncos de um metro ou dois permanecem de pé, como que amputados, em meio a cultivos prematuros. Diante dessa imagem brutal da civilização, sente-se falta da calma e da imobilidade do deserto (ibid., p. 528).

8 A despeito da posição vidaliana, sugerimos consultar a acurada análise de Diegues, que reprova o modelo norte-americano de gestão dos parques naturais, visto que, entre outras coisas, eles foram processados através da expulsão das populações tradicionais que os ocupavam (Diegues, 1996).
A bem da verdade, se em $A$ travers l'Amérique du Nord o balanço que Vidal de la Blache faz dos Estados Unidos ${ }^{8}$ é muito mais positivo que negativo, nem sempre ele foi tão generoso assim. Na resenha que dedica ao livro La Colombie britannique: étude sur la colonisation au Canada (1907), de Albert Métin, não poupa capitalistas, especuladores e engenheiros norte-americanos, para quem a fórmula make money "permanece o objetivo supremo e a preocupação dominante destas sociedades utilitárias" (Vidal de la Blache, 1908, p. 366).

Conhecendo os trabalhos de Vidal como um todo, sabemos de que movimento se trata: em relação à França, exalta-se a colonização, a necessidade da modernização e a defesa da integridade do território. Em relação à Alemanha, aos Estados Unidos e às po- 
tências imperialistas adversárias, são reprovados o desvio civilizacional, a força econômica, o ímpeto expansionista (Ribeiro, 2010a).

Em todo caso, isso não é o mais importante aqui, mas sim a relevância da experiência norte-americana na imaginação geográfica de Vidal de la Blache. Dificilmente seria possível concordar com a leitura parcial e simplificadora promovida por Numa Broc, para quem a geografia vidaliana era muito mais afeita às realidades lentamente elaboradas próprias à relação homem-meio e aos gêneros de vida do Mediterrâneo e da Ásia e, de maneira geral, a viagem à América ocorreu tarde demais para ter marcado o pensamento de Vidal (Broc, 1991, p. 643). Ampliando o espectro da questão, ao nos remetermos à história do pensamento geográfico, percebemos o quão equivocadas estão determinadas leituras, para quem nosso investigado seria um geógrafo voltado majoritariamente ao mundo rural e omisso face à modernidade. Le Bossé não se faz de rogado e escreve que a geografia vidaliana "não dava conta da irrupção da modernidade, especialmente da vida urbana, em sociedades congeladas em seus traços tradicionais” (Le Bossé, 2004, p. 165 [1999]). Já Thrift compõe um quadro onde a geografia regional de Vidal tem como elementos principais a aldeia, o campo, os donos de terras e o feudalismo como modo de produção dominante (sic). No máximo, ele (juntamente com Lacoste) admite um interesse tardio pelo urbano em La France de l'Est (Lacoste, 1988 [1976]; Thrift, 1996 [1994]).

A despeito disso, a vivência de Vidal na América torna-se ainda mais curiosa quando sabemos do trabalho apresentado por ele no Congresso em questão: Application des lignes d'équidistance à l'étude anthropologique de la Méditerranée. Trata-se, em nossa visão, de um tema e de uma área, por assim dizer, tradicionais - o homem Mediterrâneo - em seu pensamento, quando comparados à "vanguarda" representada pelo urbano e pela indústria. Em outras palavras, enquanto Vidal expunha um objeto, grosso modo, "do passado", a realidade dos Estados Unidos the mostrava o presente e, mais ainda, o devir. Afinal, como ele mesmo finaliza o texto, a América do Norte lhe proporcionava um "raro prazer": testemunhar a "preparação do futuro" (Vidal de la Blache, 1905, p. 531).

\section{REFERÊNCIAS BIBLIOGRÁFICAS}

ARRAULT, J. Une géographie innatendue: le système mondial vue par Paul Vidal de la Blache. L'espace géographique, tome 37, 1, p. 75-88, 2008.

BERMAN, M. Tudo o que é sólido desmancha no ar: a aventura da Modernidade. São Paulo: Cia. das Letras, 1986 (1982). 360p.

BRAUDEL, F. Cátedra de História de la Civilización. Enseñanza de la historia y sus directrices. Revista de Economía Institucional, v. 12, n. 22, p. 239-246, 2010 (1935).

BROC, N. Vidal de la Blache en Amérique du Nord: le congrès internationale de géographie de 1904. Annales de Géographie, n. 561-562, 1991.

CARVALHO, M. Diálogos entre as Ciências Sociais: um legado intelectual de Friedrich Ratzel (1844-1904). Biblio 3W. Revista de Geografia y Ciencias Sociales, n. 34, 1997. Disponível em: <http://www.ub.edu/geocrit/b3w-34.htm>. Acesso em: 10 dez. 2001.

. Ratzel: releituras contemporâneas. Uma reabilitação? Biblio 3W. Revista de Geografia y Ciencias Sociales, n. 25, 1997a. Disponível em: <http://www.ub.edu/geocrit/ b3w-25.htm>. Acesso em: 10 dez. 2001.

CLAVAL, P. Histoire de la Géographie française de 1870 à nos jours. Paris: Nathan, 1998. $543 \mathrm{p}$.
Guilherme Ribeiro é professor adjunto II do Departamento de Geociências da UFRRJ; coordenador do Laboratório de Política, Epistemologia e História da Geografia (LAPEHGE) - pesquisa apoiada pela FAPERJ. Email: geofilos@ig.com.br

Artigo recebido em março de 2012 e aprovado para publicação em junho de 2012. 
CLAVAL, P. Epistémologie de la Géographie. Paris: Nathan, 2001. 266p. - Géographies et géographes. Paris: L'Harmattan, 2007. 384p.

DAIX, P. Fernand Braudel: uma biografia. Rio de Janeiro: Record, 1999 (1995). 655p. MARTONNE, E. Le VIII congrès international de géographie (Washington, 1904) et sa grand éxcursion dans l'Ouest et au Mexique. Annales de Géographie, année XIV, n. 73, p. 1-22, 1905.

DIEGUES, A. C. O mito moderno da natureza intocada. São Paulo: Hucitec, 1996. 169p. FOUCAULT, M. A ordem do discurso. 11. ed. São Paulo: Loyola, 2004 (1970). 79p.

FROIDEVAUX, H. Congrès international de géographie à Washington. Journal de la Société des Américanistes, v. 2, n. 1, 1905.

HARVEY, D. Condição Pós-Moderna. São Paulo: Loyola, 1992 (1989). 349p.

LACOSTE, Y. A Geografia - isso serve, em primeiro lugar, para fazer a guerra. Campinas: Papirus, 1988 (1976). 263p.

LE BOSSÉ, M. "Questôes de identidade em Geografia Cultural: algumas concepçôes contemporâneas”. In: CORRÊA, R. L., ROSENDHAL, Z. (Orgs.). Paisagem, textos e identidade. Rio de Janeiro: Eduerj, 2004 (1999). p. 157-179.

LEFEBVRE, H. A Revolução Urbana. Belo Horizonte: Ed. da UFMG, 1999 (1970). 178p. LIMA, L. C. Fernand Braudel e o Brasil: vivência e brasilianismo (1935-1945). São Paulo: Edusp, 2009. 212p.

MATOS, O. C. F. Benjaminianas: cultura capitalista e fetichismo contemporâneo. São Paulo: Unesp, 2010. 302p.

MERCIER, G. Paul Vidal de la Blache ou la légitimation patriotique de la région et de la géographie. Revue française de géoéconomie, n. 5, printemps, p. 137-146, 1998.

. Entre science et patrie. Lecture du régionalisme de Paul Vidal de la Blache. Cahiers de Géographie du Québec, v. 45, n. 126, déc., p. 389-412, 2001.

OZOUF-MARIGNIER, M.; ROBIC, M. La France au seuil des temps nouveaux. Paul Vidal de la Blache et la régionalisation. L'Information Géographique. Paris, v. 59, p. 46-56, 1995. (Uma versão deste artigo em português foi por nós traduzida na revista Geographia [UFF] ano 9, n. 18, p. 7-31, 2007. Disponível em: <http://www.uff.br/geographia/ojs/ index.php/geographia/article/view/223>. Acesso em: 05 jan. 2011.

PARIS, E. La genèse intellectuelle de l'oeuvre de Fernand Braudel. Athènes: Institute de Recherches Néohelléniques/FNRS, 1999. 352p.

RIBEIRO, G. As apropriações do espaço no pensamento de Eric Hobsbawm: reflexões sobre a epistemologia da Geografia vista sob o olhar do outro. Niterói: Dissertação de Mestrado, PPGEO-UFF, 2004. 125p.

. Uma epistemologia em construção: diálogos entre a Geografia e a Sociologia em Paul Vidal de la Blache. Geographia (UFF), ano IX, n. 18, p. 117-122, 2007. Disponível em: <http://www.uff.br/geographia/ojs/index.php/geographia/article/ view/220/212>. Acesso em: 05 jan. 2011.

. Para além da ingenuidade: releituras vidalianas. Geographia (UFF), ano X, n. 20, p. 124-131, 2008. Disponível em: <http://www.uff.br/geographia/ojs/index.php/ geographia/article/view/257/235>. Acesso em: 05 jan. 2011.

. Espaço, tempo e epistemologia no século XX: a Geografia na obra de Fernand Braudel. Niterói: Tese de Doutorado, PPGEO-UFF, 2008a. 382p.

. Modernidade e Espaço, Pós-Modernidade e Mundo: a Crise da Geografia em tempos de Globalização. X Colóquio Internacional Geocrítica. Barcelona, maio, 2008b. Disponível em: <http://www.ub.edu/geocrit/-xcol/154.htm>. Acesso em: 05 jan. 2011. 
RIBEIRO, G. Interrogando a ciência: a concepção vidaliana de Geografia. Confins [On-line], 8, 2010. Disponível em: <http://confins.revues.org/6295>. Acesso em: 05 jan. 2011. . Território, Império e Nação: a Geopolítica em Paul Vidal de la Blache. Revista da Anpege, v. 6, jan.-dez., p. 29-42, 2010a. Disponível em:<http://www.anpege.org.br/ revista/ojs-2.2.2/index.php/anpege08/article/view/62/pdf\%203>. Acesso em: 05 jan. 2011. . Meio e técnica: uma histoire croisée a partir das contribuiçōes de Paul Vidal de la Blache, Fernand Braudel e Milton Santos. IV Seminário de Pesquisa do Instituto de Ciências da Sociedade e Desenvolvimento Regional da UFF - Campos dos Goytacazes, março (2011). Disponível em: <http://www.uff.br/ivspesr/images/Artigos/ST09/ ST09.4\%20Guilherme\%20Ribeiro.pdf>. Acesso em: 18 out. 2011.

. "Geografia Humana: fundamentos epistemológicos de uma ciência". In: HAESBAERT, R.; RIBEIRO, G.; PEREIRA, S. N. (Orgs.). Vidal Vidais. Textos de Geografia Humana, Regional e Política. Rio de Janeiro: Bertrand Brasil, 2012. (No prelo). ROBIC, M. Éloge de la circulation. Strates [En ligne]. Crises et mutations des territoires, n. 9 (1996-97). Disponível em: <http://strates.revues.org/619>. Acesso em: 15 dez. 2005. SANGUIN, A. En relisant Ratzel. Annales de Géographie, v. 99, n. 555, p. 579-594, 1990. . Vidal de la Blache (1845-1918), un génie de la Géographie. Paris: Belin, 1993. 384p.

SASSEN, S. The global city: New York, London, Tokyo. Princeton: Princeton University Press, 1991. 395p.

SAUER, C. The personality of Mexico. Geographical Review, v. 31, n. 3., jul., p. 353-364, 1941.

SCOTT, A. (Org.). Global City-Regions: trends, theory, policy. Oxford: Oxford University Press, 2001. 467p.

SOJA, E. Geografias pós-modernas: a reafirmação do espaço na teoria social crítica. Rio de Janeiro: Jorge Zahar, 1993 (1989). 324p.

SOUBEYRAN, O. Imaginaire, science et discipline. Paris: L'Harmattan, 1997. 482p.

THRIFT, N. "Visando o âmago da região". In: GREGORY, D.; MARTIN, R.; SMITH, G. (Orgs.). Geografia Humana: Sociedade, Espaço e Ciência Social. Rio de Janeiro: Jorge Zahar Editor, p. 215-247, 1996 (1994).

VIDAL DE LA BLACHE, P. La péninsule européenne. L'océan et la méditerranée. Leçon d'ouverture du cours d'histoire et géographie à la Faculté des Lettres de Nancy. Paris: Berger-Levrault, 1873. 32p.

. Leçon d'ouverture du cours de Géographie. Annales de Géographie, VIII année, n. 38, p. 97-109, 1899. (Uma versão deste artigo em português foi por nós traduzida na revista Geographia (UFF) ano 10, n. 20, 2008).

. Les conditions géographiques des faits sociaux. Annales de Géographie, année XI, n. 55, p. 13-23, 1902. (Uma versão deste artigo em português foi por nós traduzida na revista Geographia (UFF) ano 9, n. 18, 2007).

. Routes et chemins de l'ancienne France. Strates [En ligne]. Crises et mutations des territoires, n. 9, 1996-97 (1902). Disponível em: <http://strates.revues.org/ document620.html >. Acesso em: $15 \mathrm{dez}$. 2005. (Uma versão deste artigo em português foi por nós traduzida na revista Geographia (UFF) ano 8, n. 16, 2006).

. La France. "Tableau géographique". In: RIOUX, J. Tableaux de la France. Michelet, Duruy, Vidal de la Blache et Bruno. Paris: Omnibus, p. 327-783, 2007 (1903). . Rapports de la Sociologie avec la Géographie. Revue Internationale de Sociologie, 12 (5), p. 309-313, 1904. (Uma versão deste artigo em português foi por nós traduzida na revista Confins, n. 8, 2010). 
VIDAL DE LA BLACHE, P. A travers l'Amérique du Nord. La Revue de Paris, avril, p. 515-531, 1905.

. La mission militaire française au Pérou. Annales de Géographie, année XV, n. 79, p. 78-82, 1906.

. De l'interprétation géographique des paysages. Neuvième Congrès International de Géographie, Genève, 1908. (Uma versão deste artigo em português foi por nós traduzida na revista Mercator (UFC) ano 7, n. 13, p. 155-157, 2008. Disponível em: <www. mercator.ufc.br/index.php/mercator/article/viewFile/32/187>. Acesso em: 05 jan. 2011.

. La Colombie Britannique, par A. Métin. Annales de Géographie, année XVII, n. 94, p. 364-366, 198a.

. L’Afrique central française, par A. Chevalier. Annales de Géographie, année XVII, n. 92, p. 165-171, 1908b.

. Régions Françaises. La Revue de Paris, déc., p. 821-849, 1910.

. La relativité des divisions régionales. Athéna, Conférence à l'École des Hautes Études Sociales, p. 1-14, 1911.

. Les genres de vie dans la géographie humaine. Second article. Annales de Géographie, année XX, n. 112, p. 289-304, 1911a.

. Les chemins de fer en Amérique. France-Amérique, février, p. 69-78, 1912.

. Évolution de la population en Alsace-Lorraine et dans les départements

limitrophes. Annales de Géographie, XXV année, n. 133 p. 97-115, 1916.

. La rénovation de la vie régionale. Foi et Vie, Les questions du temps présent,

Cahier B, n. 9, maio, p. 103-110, 1917.

. La France de l'Est (Lorraine-Alsace). Paris: La Découverte, 1994 (1917).

285p.

. Princípios de Geografia Humana. Lisboa: Cosmos, 1954 (1921). 387p.

VLACH, V. R. F. Acerca da geografia, da política, da geograficidade: fragmentos metodológicos. Sociedade \& Natureza, ano 11, n. 21 e 22, jan.-dez., p. 97-109, 1999.

ZIMMERMANN, M. Le VIIIe Congrès International de Géographie. Annales de Géographie, année XIII, n. 72, p. 467-468, 1904.

A B S T R A C T Taking as a starting point the article A travers l'Amérique du Nord published in 1905 in La Revue de Paris, this paper analyzes the impacts of the American experience in Vidal de la Blache's geography studies. Emphasizing his concern for the urban phenomenon, we present the geographer as an important analyst of the modernity.

K E Y W O R D S Modernity; urbanization; United States; Paul Vidal de la Blache; geography. 